\section{Suicide by hanging: multicentre study based on coroners' records in England}

\author{
OLIVE BENNEWITH, DAVID GUNNELL, NAVNEET KAPUR, \\ PAULINE TURNBULL, SUE SIMKIN, LESLEY SUTTON and KEITH HAWTON
}

\begin{abstract}
Summary We studied 162 cases of hanging by suicide occurring in 24 coroners' jurisdictions in England within a 6-month period in 2001. Prison and psychiatric ward suicides accounted for only $6 \%$ of these. The most frequently used ligatures (ropes, belts and cable) and ligature points (beams, girders, lofts and trees) are commonly available in community settings, limiting opportunities for prevention. In only half the cases (52\%) were victims fully suspended with both feet off the ground. Four per cent had also taken an overdose.
\end{abstract}

\section{Declaration of interest None.}

Hanging is the most common method of suicide in England and Wales, accounting for about 2000 deaths each year (Department of Health, 2002; Brock \& Griffiths, 2003). Previous studies have been confined to specific geographical locations and have not comprehensively investigated potentially preventable aspects of these deaths (Bowen, 1982; Davison \& Marshall, 1986; James \& Silcocks, 1992).

In this short report we describe a large case series of hanging suicides from a wide geographical area focusing on the possibilities for restricting access to means, which is one of the objectives of the National Suicide Prevention Strategy for England (Department of Health, 2002).

\section{METHOD}

We studied hanging suicides occurring within the jurisdictions of 24 coroners between 1 July 2001 and 31 December 2001. We initially approached the coroners serving the 3 research centres (Oxford, Bristol and Manchester). A further 21 coroners, 7 from each centre, were randomly selected from a list of coroners within 50 miles (or 1.5 hours' travelling time) of each centre. Three coroners, from 2 centres, did not agree to participate; they were replaced with the next randomly selected coroners in the relevant centres. Five of the jurisdictions were urban, 15 mixed urban/rural and 4 rural. All deaths by hanging or selfstrangulation given a suicide or open verdict were examined.

We collected demographic data, information on the timing and location of the act, who discovered the person, whether they were alive when found, whether alcohol or drugs had been consumed (including details of toxicology reports), contact with psychiatric services, whether the person was suffering from a psychiatric disorder at the time of death and their history of self-harm. Psychiatric diagnoses were based on both general practitioner and psychiatric reports. Where the individual had not had contact with a psychiatrist, diagnoses were formulated on the basis of witness accounts. Information on the ligature, ligature point and degree of suspension was recorded.

\section{RESULTS}

One hundred and sixty-two cases of hanging $(85.8 \%$ males $)$ were identified across the 24 districts. A verdict of death by suicide was returned in nearly all cases (155 out of $162,95.7 \%$ ). The remainder $(4.3 \%)$ were recorded as open verdicts. Seven individuals $(4.3 \%)$ had engaged in simultaneous self-poisoning.

\section{Demographic characteristics}

Mean ages were similar in males (40.6 years) and females (42.2 years). Eleven individuals $(6.8 \%)$ were psychiatric inpatients and $5(3.1 \%)$ were prisoners. Only $5(3.1 \%)$ of the psychiatric in-patients died on the ward.

\section{Contact with psychiatric services and psychiatric diagnosis}

Information on contact with psychiatric services was available for 117 individuals $(72.2 \%)$. Forty-eight of these $(41.0 \%)$ were in contact with a psychiatric service at the time of death.

Among the 128 cases where an assessment of psychiatric disorder was possible, more than half ( 71 out of $128,55.5 \%$ ) had a primary diagnosis of affective disorder and $13.3 \%$ had schizophrenia (17 out of 128). Information on past self-harm was recorded for most individuals (152 out of $162,93.8 \%$ ). Nearly half of these had previously self-harmed (68 out of 152, 44.7\%).

\section{Location of death and discovery}

In two-thirds of cases (106 out of 162, $65.4 \%$ ) the person hanged themselves at their home, either indoors or in their garden, shed or garage. In 27 cases the death occurred outside in a public area. Sixtyeight individuals $(42 \%)$ were found by a family member or partner. In 7 of the 162 cases $(4.3 \%)$ the individual was found alive and was taken to hospital.

\section{Ligatures used for hanging}

Where this was recorded ( $98.8 \%$ of cases) the main ligatures used were rope or cord $(49.4 \%)$, belt $(13.1 \%)$, electric cable $(11.9 \%)$, and $\operatorname{dog}$ lead $(6.3 \%)$. Items of clothing other than a belt (scarf, tie, dressing gown cord, shoe-lace) were used in one-tenth of hangings (16 out of 160 , $10.0 \%)$. Information on the source of the ligature was available for only 73 cases $(45.1 \%)$. In most (63 out of $73,86.3 \%$ ) this had been in the household at the time.

\section{Suspension points and type of suspension}

Roofs and ceilings (beam/girder or loft) were used as ligature points in about onethird of hangings (58 out of $162,35.8 \%$ ) (see Table 1). Of the outdoor ligature points, a tree was most commonly used (25 out of $162,15.4 \%$ ).

Information on degree of suspension was available for 149 cases. Seventy-eight of these $(52.4 \%)$ were found totally suspended (both feet above the ground). In about one-quarter (35 out of $149,23.5 \%$ ) the subjects were suspended with their feet touching the ground, in 11 cases $(7.4 \%)$ they were kneeling, in 13 lying $(8.7 \%)$ 
Table I Ligature point used

\begin{tabular}{|c|c|}
\hline Ligature point used & $n(\%)$ \\
\hline Beam/girder & $27(16.7)$ \\
\hline Tree & $25(15.4)$ \\
\hline Loft hatch (includes bar across hatch) & $20(12.4)$ \\
\hline Loft beam & $8(4.9)$ \\
\hline Loft (no further information) & $3(1.9)$ \\
\hline Banister & $15(9.3)$ \\
\hline Back of door & $13(8.0)$ \\
\hline Cupboard or wardrobe & $7(4.3)$ \\
\hline Window frame & $6(3.7)$ \\
\hline Curtain or shower rail & $4(2.5)$ \\
\hline Cell bars/window & $4(2.5)$ \\
\hline Hook or door handle & $3(1.9)$ \\
\hline Balcony/stairs & $3(1.9)$ \\
\hline Wall bracket/railing/fence & $3(1.9)$ \\
\hline Bridge & $2(1.2)$ \\
\hline Pipe or radiator & $2(1.2)$ \\
\hline Shelving & $2(1.2)$ \\
\hline Bed & $2(1.2)$ \\
\hline Exercise rail/bar & $2(1.2)$ \\
\hline Climbing frame/playhouse & $2(1.2)$ \\
\hline Other' & $9(5.4)$ \\
\hline
\end{tabular}

I. Other: ladder (I), door frame (I), rail across toilet cubicle (I), control box for garage door (I), shed (specific ligature point not stated) (I), airing cupboard (specific

point not stated) (I), roof of wendy house (I), fire

escape stairs (I), outhouse (specific point not stated) (I).

and in 7 seated $(4.7 \%)$. The precise position was unclear in a further 5 cases involving partial suspension $(3.4 \%)$.

\section{Hanging suicides in prison and psychiatric wards}

All prison hanging suicides $(n=5)$ took place in the prison cell. In 4 cases the ligature point used was the cell bars/window and in one case the toilet door. Sheeting (usually torn) was the ligature in 4 cases.

Three of the 5 hanging suicides which occurred on psychiatric wards used a belt and in one case a dressing gown cord. Ligature points used were a radiator fitting, a pipe (in the bathroom), part of the bed (metal bedhead), a wardrobe handle and the bed curtain rail.

\section{DISCUSSION}

The most common ligatures used in this sample (rope, belts and flex) are similar to those found in previous community-based

OLIVE BENNEWITH, BA, DAVID GUNNELL, PhD, FFPH, Department of Social Medicine, University of Bristol; NAVNEET KAPUR, MD, MRCPsych, PAULINE TURNBULL, BA, Department of Psychiatry and Behavioural Sciences, Manchester Royal Infirmary, Manchester; SUE SIMKIN, BA, LESLEY SUTTON, MSc, KEITH HAWTON, DSc, FRCPsych, Centre for Suicide Research, University Department of Psychiatry, Warneford Hospital, Oxford OX3 7JX, UK

Correspondence: Professor David Gunnell, Department of Social Medicine, Canynge Hall, Whiteladies Road, Bristol BS8 2PR, UK. Tel: +44 (0) 117928 7253; e-mail: D.J.Gunnell@Bristol.ac.uk

(First received 25 March 2004, final revision 14 September 2004, accepted 29 September 2004)

studies (see, for example, Davison \& Marshall, 1986). Although information regarding from where these ligatures had been obtained was rarely noted in coroners' records, they are easily available. Similarly the main ligature points used (beams, girders, lofts and trees) are commonly available. It would appear, therefore, that restricting access to ligatures outside institutional settings is not possible.

Suicides in institutions (prisons and psychiatric hospital wards) made up only a small proportion of the total hanging suicides $(6.2 \%)$. Nevertheless such suicides are potentially preventable through environmental modification (Appleby et al, 2001; Burrows et al, 2003; Shaw et al, 2003). The ligature point used in one of the psychiatric ward suicides - the bed curtain rail - should no longer be available in psychiatric units as trusts were required by law to remove non-collapsible bed curtain rails by March 2002 (National Institute for Mental Health in England, 2003). Environmental audits, planned as part of the National Suicide Prevention Strategy to minimise the risk of hanging (National Institute for Mental Health in England, 2003), need to take into account, when assessing potential ligature points, the finding that nearly half of all suicides do not involve full suspension. The prison hangings identified in our study could not have been carried out in a full specification (ligaturefree) 'safer cell' (Burrows et al, 2003).

In 7 cases of hanging the person also self-poisoned. If those who hang themselves are found alive, and treatment focuses on the hanging alone without investigation of possible additional suicide methods, the episode may still be fatal.

As it may not be possible to prevent hanging suicides through the restriction of access to ligatures and ligature points outside institutional settings, the focus needs to be on understanding the reasons for the use of this method and the prevention of factors leading to suicide generally.

\section{ACKNOWLEDGEMENTS}

We thank the coroners who gave us access to their records and their staff who also gave us assistance.

This research was funded by the Department of Health. Views expressed in this paper are those of the authors and not necessarily those of the Department of Health.

\section{REFERENCES}

Appleby, L., Shaw, J., Sherratt, J., et al (200I) Safety First: Five-year report of the National Confidential Enquiry into Suicide and Homicide by People with Mental Illness. London: Department of Health.

Bowen, D. A. (1982) Hanging - a review. Forensic Science International, 20, 247-249.

Brock, A. \& Griffiths, C. (2003) Trends in suicide by method in England and Wales, 1979 to 200I. Health Statistics Quarterly, 20, 7-18.

Burrows, T., Brock, A. P., Hulley, S., et al (2003) Safer Cells Evaluation: Full Report. London: The jill Dando Institute of Crime Science, University College London.

Davison, A. \& Marshall, T. K. (1986) Hanging in Northern Ireland - a survey. Medicine, Science and the Law, 26, 23-28.

Department of Health (2002) National Suicide Prevention Strategy for England. London: Department of Health.

James, R. \& Silcocks, P. (1992) Suicidal hanging in Cardiff - a 15-year retrospective study. Forensic Science International, 56, 167-175.

National Institute for Mental Health in England (2003) The National Suicide Prevention Strategy for England: Annual Report on Progress 2003. Leeds: National Institute for Mental Health in England.

Shaw, J., Appleby, L. \& Baker, D. (2003) Safer Prisons: A National Study of Prison Suicides 1999-2000 by the National Confidential Inquiry into Suicides and Homicides by People with Mental IIIness. London: Department of Health. 